\title{
ANALISIS LOAN TO DEPOSIT RATIO (LDR) DAN NON PERFORMING LOAN (NPL) PADA PT. BANK NEGARA INDONESIA 1946 (Persero) Tbk.
}

\author{
Yolanda Tri Marta Fitri, Jhon Fernos \\ Akademi Keuangan dan Perbankan "Pembangunan" Padang \\ yolandatrimartafitri@gmail.com
}

\begin{abstract}
The purpose of this study is to determine the analysis of Loan to Deposit Ratio (LDR) and Non Performing Loans (NPL) at PT. Bank Negara Indonesia 1946 (Persero) Tbk. In analyzing the data, the authors used quantitative data analysis methods. Quantitative data is information data that is expressed in the form of figures from the calculation and measurement of the Loan To Deposit Ratio (LDR) and Non Performing Loan (NPL) analysis at PT. Bank Negara Indonesia 1946 (Persero) Tbk. The results of this study indicate that in the period 2017 - 2019 the Loan Deposit to Ratio (LDR) from the evaluation results is quite healthy because the average value is $89 \%$ with the evaluation criteria matrix is in the position > $75 \%$ LDR $<100 \%$ and Non Performing Loans (NPL evaluation results are classified as healthy because NPL $<5 \%$.
\end{abstract}

Keywords : Loan To Deposit ratio (LDR),Non Performing Loan (NPL)

\section{PENDAHULUAN}

Bank ialah suatu lembaga keuangan yang memegang peranan sangat penting dalam perbaikan sistem keuangan pendapatan masyarakat. Bank Negara Indonesia merupakan bank BUMN dan bank lainnya, yang sampai sekarang ini belum mampu menjangkau semua lapisan masyarakat terutama daerah pedesaan. Apalagi ada kaitannya sesuai dengan fungsi bank yaitu kredit. Dengan keadaan begitu, maka pembangunan daerah didirikan oleh bank sesuai lembaga pemerintah, yang mana hampir setiap daerah mendapatkan layanan perbankan bagi mereka yang tidak memperoleh pelayanan langsung dari bank umum.

Berdasarkan UU No. 10 Tahun 1998 pasal 1 (2) menyatakan bank adalah suatu lembaga keuangan yang menghimpunkan dana dari masyarakat (bentuk simpanan) dan menyalurkannya kembali kepada masyarakat (bentuk kredit) atau bentuk lainnya, berguna untuk kesejahteraan masyarakat. Sedangkan menurut Widayati \& Mendari (2019) pengertian bank merupakan lembaga yang menghubungkan antara pihak yang kelebihan dana dan pihak yang kekurangan dana, memperlancar arus pembayaran, serta mencari laba yang besar dalam usaha yang dilakukannya.

Berdasarkan UU No. 10 Tahun 1998, kredit merupakan tagihan yang muncul diakibatkan oleh perjanjian pinjam meminjam yang terjadi di antara dua pihak (bank dengan calon nasabah) yang mana mewajibkan nasabah memenuhi kewajibannya berdasarkan rentang waktu yang disepakati beserta bunganya. Sedangkan menurut Widayati \& Maiwati (2019) pengertian kredit adalah tagihan 
yang muncul akibat kesepakatan antara kreditur (bank) dan pihak debitur, yang mana pihak debitur wajib melunasi kewajibannya sesuai jangka waktu yang ditentukan dan bunganya.

Non Performing Loan (NPL) adalah suatu alat yang menilai kesanggupan bank dalam mengelola kredit bermasalah. Kredit bermasalah yang ditimbulkan adalah salah satu risiko bank, yang diakibatkan oleh ketidakpastian pelunasan hutang dari debitur atas pinjaman yang diberikan bank (Hasibuan \& Puspitasari, 2007). Akibatnya dapat menurunkan kinerja bank sehingga perusahaan menjadi tidak efisien. Untuk penilaiannya dapat dilihat dari penjelasan berikut: "Semakin tinggi rasio NPL maka semakin buruk kualitas kredit bank sehingga mengakibatkan kerugian, begitupun sebaliknya jika semakin rendah NPL maka keuntungan bank akan semakin meningkat".

Menurut Yati \& Afriyeni (2019) Loan to Deposit Ratio (LDR) adalah perbandingan untuk menilai kesanggupan bank dalam memenuhi hutang jangka pendek sesuai dengan harta bank (atau disebut juga dengan likuiditas), sedangkan menurut Kasmir \& Pasaribu (2003) Loan to Deposit Ratio (LDR) adalah perbandingan yang digunakan untuk memperkirakan jumlah kredit dengan jumlah dana masyarakat sesuai dengan modal bank. Rasio ini digunakan untuk mengetahui kesanggupan bank dalam melunasi hutangnya kembali, sehingga mampu menerima permohonan kredit dari calon debitur lainnya.

Meningkatnya jumlah kredit macet yang diperoleh dari nasabah sangat mempengaruhi kesanggupan bank dalam menyelesaikan hutangnya. Penyebab utamanya berasal dari internal bank yaitu kurang hati-hati dalam memberikan pinjaman. Akibatnya bagi nasabah (pihak eksternal) yang tidak bisa melunasi kewajibannya menjadi menunggak. Akhirnya perusahaan tidak bisa memberikan kredit untuk calon debitur lainnya, sehingga keuntungan yang menjadi tujuan bank tidak dapat terwujudkan.

PT. Bank Negara Indonesia 1946 (Persero) Tbk. merupakan perusahaan yang memberikan pinjaman terhadap nasabah yang membutuhkan dana. Fasilitas layanan ini disediakan bank untuk meminjamkan uang yang digunakan debitur sesuai kesepakatan antara peminjam dengan orang yang memberikan pinjaman. Dengan keberadaan PT. Bank Negara Indonesia 1946 (Persero) Tbk. maka bank berfungsi memberikan kemudahan untuk nasabah dalam membuka dan menjalankan usahanya agar lancar, terutama bagi masyarakat yang kekurangan. Dengan demikian usaha yang dijalankan tercapai sesuai dengan sasaran yang diinginkan.

\section{Tabel 1}

Data Laporan Keuangan

\section{PT. Bank Negara Indonesia 1946 (Persero)}

Tbk Periode 2017-2019

(dalam Rp.000.000,-)

\begin{tabular}{cccc}
\hline Tahun & $\begin{array}{c}\text { Total Kredit Yang } \\
\text { Diberikan }\end{array}$ & $\begin{array}{c}\text { Total Dana } \\
\text { Pihak Ketiga }\end{array}$ & $\begin{array}{c}\text { Total Kredit } \\
\text { Bermasalah }\end{array}$ \\
\hline 2017 & 417.151 .310 & 487.461 .507 & 2.920 .059 \\
2018 & 483.421 .821 & 544.659 .543 & 4.109 .085 \\
2019 & 522.750 .099 & 571.075 .697 & 6.534 .376 \\
\hline
\end{tabular}

Sumber: http//www.ojk.go.id, Tahun 2021 
Dari tabel 1 di atas dapat diketahui bahwa Loan to Deposit Ratio (LDR) mengalami peningkatan dari tahun 2017 sampai 2019 berdasarkan jumlah pinjaman yang diberikan dan jumlah dana pihak ketiga (DPK). Begitupun dengan Non Performing Ratio(NPL) mengalami peningkatan dari tahun 2017 sampai 2019 berdasarkan jumlah kredit bermasalah dan jumlah pinjaman yang diberikan.

\section{METODE PENELITIAN}

\section{Metode Pengumpulan Data}

Untuk penelitian ini, pengumpulan data dilakukan dengan dua cara yaitu: a. Studi kepustakaan (Library Research) merupakan kegiatan dalam memperoleh informasi yang signifikan sesuai dengan masalah objek penelitian yang diperoleh dari mempelajari buku-buku, karya ilmiah, internet, dan sumber lainnya. b. Studi Lapangan (Field Research) merupakan pengamatan secara langsung di lokasi kegiatan yang dilandasi pengalaman dan pengetahuan secara teoritis dalam menggali dan mengumpulkan objek yang diteliti berupa data, serta melakukan penyusunan data/informasi yang diperoleh guna sebagai pemecahan masalah laporan keuangan.

\section{Metode Analisa Data}

Pada analisis data penulis menggunakan data kuantitatif sebagai metode penelitian, dimana metode kuantitatif tersebut kegiatannya adalah mencari data berupa angka-angka selama kegiatan penelitian berlangsung. Dalam metode ini penulis menjelaskan data secara fakta yang dialami sesuai dengan teori yang ada.

\section{HASIL DAN PEMBAHASAN \\ Pengertian Bank}

Menurut Undang-Undang No.10 Tahun 1998 tentang perubahan UndangUndang No. 7 Tahun 1992, Bank merupakan badan usaha yang kegiatannya menghimpun dana (simpanan) dan menyalurkannya kepada masyarakat (kredit) untuk meningkatkan taraf hidup masyarakat banyak. Aset keuangan (financial assets) adalah suatu kekayaan yang dimiliki oleh bank. Dananya dapat diperoleh dari masyarakat yang kelebihan dana.

\section{Jenis-jenis Bank}

Menurut Undang-Undang No. 10 Tahun 1998 perubahan atas UndangUndang No. 7 tahun 1992, jenis bank dilihat fungsinya, antara lain:

a. Dilihat dari segi fungsinya, dapat dibagi menjadi:

1) Bank Umum adalah suatu badan keuangan yang menjalankan tugasnya secara konvensional dan atau berdasarkan prinsip syariah kepada seluruh masyarakat dan dalam menjalankan tugasnya memberikan jasa lalu lintas pembayaran.

2) Bank Perkreditan Rakyat (BPR) adalah suatu badan usaha yang menjalankan tugasnya secara konvensional atau berdasarkan prinsip syariah kepada seluruh masyarakat yang dalam menjalankan tugasnya tidak memberikan jasa dalam lalu lintas pembayaran.

b. Dilihat dari segi kepemilikannya, dapat dibagi menjadi:

1) Bank Milik Pemerintah adalah suatu usaha yang pemiliknya adalah pemerintah pusat yang dananya berasal dari modal sendiri beserta dengan 
pendiriannya. Keuntungan yang diperoleh juga seutuhnya dimiliki oleh pemerintahan. Begitupun dengan Bank Milik Pemerintah Daerah adalah badan usaha yang pemiliknya berasal dari pemerintah daerah yang modal dan pendiriannya juga berasal dari pemerintah. Begitupun juga dengan keuntungannya.

2) Bank Milik Swasta Nasional adalah suatu usaha yang dimiliki oleh pihak swasta, baik modal dan pendiriannya berasal dari pihak swasta, tidak termasuk modal pemerintah didalamnya. Dan keuntungan juga merupakan milik pihak swasta.

3) Bank Milik Asing adalah suatu usaha yang berasal dari bank yang berada di luar negeri, baik dari pihak swasta asing maupun pemerintah asing yang berada di luar negeri, begitupun dengan keuntungannya juga dimiliki oleh bank milik asing.

4) Bank Milik Campuran adalah suatu usaha yang sahamnya dimiliki oleh pihak asing dan pihak swasta nasional. Dalam mendirikan perusahaan dan memperoleh profit akan dibagi sesuai dengan hak masing-masing.

\section{Pengertian Kredit}

Menurut UU No. 10 Tahun 1998, kredit merupakan tagihan yang muncul diakibatkan oleh perjanjian pinjam meminjam antara bank dengan calon nasabah yang mana mewajibkan pihak debitur melunasi utangnya sesuai waktu tertentu beserta bunganya. Dalam mengembalikan kredit apabila nasabah terlambat atau tidak tepat waktu, maka akan dikenakan sanksi berupa denda.

Adapun hal yang perlu diperhatikan pihak bank dalam memberikan pinjaman kepada nasabah, antara lain:

a. Character (Karakter)

Dimana kreditur mencari terlebih dahulu tentang karakter calon debitur. Datanya berhubungan dengan bagaimana watak, sifat dan sikap pribadi, serta kejujuran yang dapat dipertanggungjawab sesuai perjanjian antara kedua belah pihak.

b. Capacity (Kemampuan)

Dimana kreditur dapat menilai kesanggupan calon debitur dalam membayarkan pinjaman sesuai kesepakatan awal, dikarenakan hal ini juga menyangkut tentang keuntungan yang akan diperoleh bank dari kegiatan penyaluran dananya.

c. Capital (Modal)

Merupakan modal atau keuangan (financial) yang dimiliki oleh calon nasabah. Dengan adanya modal dari pihak nasabah, maka dapat dilihat berapa nominal dana yang diperlukan untuk membuka bisnis. Oleh karena itu, bank dapat menyalurkan kredit kepada calon debitur.

d. Collateral (Jaminan)

Hal ini sangat penting diperhatikan oleh pihak calon nasabah maupun bank sebagai kreditur. Jika calon nasabah tidak mampu tepat waktu membayarkan kembali utangnya, maka jaminan dapat dijadikan sebagai penggantinya dengan nilai harga lebih tinggi daripada jumlah pinjaman. Jaminan tersebut dapat berupa orang, barang ataupun surat berharga lainnya. Maka jaminan yang diberikan akan dilelang oleh pihak bank sesuai dengan harga pasar. 
e. Condition of Economy (Kondisi Ekonomi)

Hal ini berkaitan erat dengan keadaan suatu negara, dimana bank harus memperhatikan keadaan ekonomi, keadaan si peminjam, keadaaan pemasaran, prospek usaha serta kebijakan pemerintah yang dapat mempengaruhi perekonomian negara.

\section{Analisis Loan To Deposit Ratio (LDR)}

Loan to Deposit Ratio (LDR) adalah perbandingan yang digunakan untuk menaksirkan kesanggupan bank memenuhi hutangnya sesuai dengan harta dari bank atau likuiditas (Afriyeni dan Yati, 2018). Likuiditas sangat penting dalam kestabilan perbankan. Untuk itu bank akan berupaya agar mampu memberikan kredit kepada setiap calon nasabahnya. Dengan lancarnya pinjaman tersebut, maka bank akan memperoleh profit yang mampu menunjang keberhasilan bank. Sesuai dengan Peraturan Bank Indonesia No. 17/II/PBI/2015 besaran rasio (LDR) dihitung dengan menggunakan rumus:

$\mathrm{LDR}=\frac{\text { Total Kredit yang Diberikan }}{\text { Total Dana Pihak Ketiga }} \times 100 \%$

Adapun kriteria penilaiannya berdasarkan peringkat komponen LDR dapat dilihat pada tabel dibawah ini:

\section{Tabel 2}

Kriteria Penilaian Tingkat Kesehatan Loan to Deposit Ratio (LDR)

\begin{tabular}{lc}
\hline \multicolumn{1}{c}{ Rasio } & Kriteria Penilaian \\
\hline LDR $75 \%$ & Sangat Sehat \\
$75 \%<$ LDR $\leq 85 \%$ & Sehat \\
$85 \%<$ LDR $\leq 100 \%$ & Cukup Sehat \\
$100 \%<$ LDR $\leq 120 \%$ & Tidak Sehat \\
LDR $>120 \%$ & Sangat Tidak Sehat \\
\hline
\end{tabular}

Sumber : Surat Edaran BI No. 6/23/DPNP/2004

Berdasarkan tabel 2 diatas, dapat dilihat bahwasannya batas aman dari penilaian LDR suatu bank adalah sekitar 75\%, namun batas maksimalnya adalah $100 \%$. Jika nilai LDR berada dibawah $75 \%$ berarti tidak baik bagi bank, hal tersebut disebabkan oleh dana yang terlalu lama disimpan maka bank akan mengalami kerugian. Sedangkan jika LDR melewati $120 \%$ maka akan menyebabkan semakin rendahnya kemampuan likuiditas bank, hal tersebut dikarenakan jumlah dana yang diperlukan untuk membiayai kredit sangat tinggi sementara danaya yang tersedia tidak mencukupi. Berdasarkan data yang diperoleh Loan to Deposit Ratio (LDR) PT. Bank Negara Indonesia 1946 (Persero) Tbk, periode Desember 2017 sampai dengan Desember 2019 dapat dijelaskan seperti dibawah ini: 
Tabel 3

Perhitungan Loan To Deposit Ratio ( LDR )

PT. Bank Negara Indonesia 1946 (Persero) Tbk.

Periode 2017-2019

( dalam Rp.000.000,- )

\begin{tabular}{lcccc}
\hline No & Tahun & $\begin{array}{c}\text { Total Kredit Yang } \\
\text { Diberikan }\end{array}$ & $\begin{array}{c}\text { Total Dana Pihak } \\
\text { Ketiga }\end{array}$ & $\begin{array}{c}\text { Loan Deposit To } \\
\text { Ratio } \\
\text { ( LDR ) }\end{array}$ \\
\hline 1 & 2017 & 417.151 .310 & 487.461 .507 & $86 \%$ \\
2 & 2018 & 483.421 .821 & 544.659 .543 & $89 \%$ \\
3 & 2019 & 522.750 .099 & 571.075 .697 & $92 \%$ \\
\hline
\end{tabular}

Sumber: http//www.ojk.go.id, data olahan

Tahun 2017 :

$$
\begin{aligned}
\text { LDR } & =\frac{\text { Total Kredit yang Diberikan }}{\text { Total Dana Pihak Ketiga }} \times 100 \% \\
& =\frac{\text { Rp. } 417.151 .310}{\text { Rp. } 487.461 .507} \times 100 \% \\
& =86 \%
\end{aligned}
$$

Berdasarkan perhitungan Loan to Deposit Ratio (LDR) PT. Bank Negara Indonesia 1946 (Persero) Tbk pada Desember 2017 adalah 86\%. Untuk standar kriteria Bank Indonesia cukup sehat, karena nilainya kecil daripada LDR.

Tahun 2018 :

$$
\begin{aligned}
\text { LDR } & =\frac{\text { Total Kredit yang Diberikan }}{\text { Total Dana Pihak Ketiga }} \times 100 \% \\
& =\frac{\text { Rp. } 483.421 .821}{\text { Rp. } 544.659 .543} \times 100 \% \\
& =89 \%
\end{aligned}
$$

Berdasarkan perhitungan Loan to Deposit Ratio (LDR) PT. Bank Negara Indonesia (Persero) Tbk. pada Desember 2018 adalah 89\%. Untuk standar kriteria Bank Indonesia cukup sehat, karena nilainya kecil daripada LDR.

\section{Tahun 2019:}

$$
\begin{aligned}
\text { LDR } & =\frac{\text { Total Kredit yang Diberikan }}{\text { Total Dana Pihak Ketiga }} \times 100 \% \\
& =\frac{\text { Rp. } 522.750 .099}{\text { Rp. } 571.075 .697} \times 100 \% \\
& =92 \%
\end{aligned}
$$

Berdasarkan perhitungan Loan to Deposit Ratio (LDR) PT. Bank Negara Indonesia (Persero) Tbk pada Desember 2019 adalah 92\%. Untuk standar kriteria Bank Indonesia cukup sehat, karena nilainya kecil daripada LDR.

\section{Analisis Non Performing Loan (NPL)}

Menurut Asrof \& Soebagio (2005) mengatakan bahwa kredit bermasalah adalah bagian dari resiko pembayaran, khususnya apabila sumber pembayaran yang diharapkan tidak cukup tersedia untuk membayar utang, namun faktor lain penyebabnya adalah kegagalan pembayaran kembali dari kesepakatan yang diharapkan tertundanya penerimaan yang berpotensi munculnya kerugian. Oleh 
karena itu, agar tidak merugikan perusahaan sebaiknya cepat diselesaikan dengan tindakan yang tepat. Artinya, semakin besarnya kredit bermasalah akan semakin memburuk keadaan yang diterima bank, karena yang diharapkan tidak sesuai dengan keuntungan yang diinginkan. Untuk menilai bank terhadap rasio NPL, maka Bank Indonesia menetapkan kriterianya yaitu keadaan bank sehat pada nilai 5\%, jika melewati batas maka bank tersebut dikatakan tidak sehat. Sesuai dengan Peraturan Bank Indonesia No. 17/II/PBI/2015 besaran rasio Non Performing Loan (NPL) dihitung dengan menggunakan rumus:

$$
\mathrm{NPL}=\frac{\text { Total Kredit Bermasalah }}{\text { Total Kredit Yang Diberikan }} \times 100 \%
$$

Berdasarkan data yang diperoleh Non Performing Loan (NPL) PT. Bank Negara Indonesia 1946 (Persero) Tbk. Desember 2017 sampai dengan Desember 2019 dapat dijelaskan pada tabel seperti dibawah ini :

\section{Tabel 4}

Perhitungan Non Performing Loan (NPL)

PT. Bank Negara Indonesia 1946 (Persero) Tbk.

Periode 2017-2019

(dalam Rp.000.000,- )

\begin{tabular}{lllcc}
\hline No & Tahun & Total Kredit Bermasalah & $\begin{array}{c}\text { Total Kredit } \\
\text { Yang } \\
\text { Diberikan }\end{array}$ & $\begin{array}{c}\text { NPL } \\
(\mathbf{1 : 2} \text { x } \\
\mathbf{1 0 0 \%}\end{array}$ \\
\hline 1 & 2017 & $2.920 .059,17$ & 417.151 .310 & $0,70 \%$ \\
2 & 2018 & $4.109 .085,48$ & 483.421 .821 & $0,85 \%$ \\
3 & 2019 & $6.534 .376,23$ & 522.750 .099 & $1,25 \%$ \\
\hline
\end{tabular}

Sumber:http//www.ojk.go.id, data olahan

Tahun 2017 :

$$
\begin{aligned}
\text { NPL } & =\frac{\text { Total Kredit Bermasalah }}{\text { Total Kredit Yang Diberikan }} \times 100 \% \\
& =\frac{\text { Rp. } 2.920 .059,17}{\text { Rp. } 417.151 .310} \times 100 \% \\
& =0,70 \%
\end{aligned}
$$

Berdasarkan perhitungan Non Performing Loan(NPL) PT. Bank Negara Indonesia 1946 (Persero) Tbk. tahun 2017 adalah 0,70\% dengan jumlah kreditnya 417.151.310, dimana berdasarkan ketetapan Bank Indonesia termasuk baik karena berada dibawah 5\% atau kecil dari NPL.

Tahun 2018:

$$
\begin{aligned}
\text { NPL } & =\frac{\text { Total Kredit Bermasalah }}{\text { Total Kredit Yang Diberikan }} \times 100 \% \\
& =\frac{\text { Rp. } 4 \cdot 109.085,48}{\text { Rp. } 483 \cdot 421.821} \times 100 \% \\
& =0,85 \%
\end{aligned}
$$

Berdasarkan perhitungan Non Performing Loan (NPL) PT. Bank Negara Indonesia 1946 (Persero) Tbk. tahun 2018 adalah 0,85\% dengan jumlah kreditnya 483.421.821, dimana berdasarkan ketetapan Bank Indonesia termasuk karena berada dibawah $5 \%$ atau kecil dari NPL. 
Tahun 2019 :

$$
\begin{aligned}
\text { NPL } & =\frac{\text { Total Kredit Bermasalah }}{\text { Total Kredit Yang Diberikan }} \times 100 \% \\
& =\frac{\text { Rp. } 6.534 .376,23}{\text { Rp. } 522.750 .821} \times 100 \% \\
& =1,25 \%
\end{aligned}
$$

Berdasarkan perhitungan Non Performing Loan (NPL) PT. Bank Negara Indonesia 1946 (Persero) Tbk. tahun 2019 adalah 1,25\% dengan jumlah kreditnya 522.750.821, dimana berdasarkan ketetapan Bank Indonesia termasuk baik karena berada dibawah 5\% atau kecil dari NPL.

Berdasarkan perhitungan analisis yang dilakukan, bahwa tingkat Loan to Deposit Ratio (LDR) pada PT. Bank Negara Indonesia 1946 (Persero) Tbk. Periode 2017 - 2019 meningkat selama tiga tahun terakhir. Pada Tahun 2018 senilai 89\% mengalami peningkatan sebesar 3\% dari tahun 2017, selanjutnya tahun 2019 senilai 92\% mengalami peningkatan sebesar 2\% dari tahun 2018. Hal itu sesuai dengan ketentuan Standar Bank Indonesia bahwa Loan Deposit To Ratio (LDR) pada bank PT. Bank Negara Indonesia 1946 (Persero) Tbk termasuk kedalam kriteria sehat, dikarenakan kecil dari $100 \%$.

Non Performing Loan (LDR) pada PT. Bank Negara Indonesia 1946 (Persero) Tbk. Periode 2017-2019 berada pada keadaan baik (sehat) dikarenakan nilainya berada dibawah 5\%. Pada tahun 2017- 2019 berturut-turut sebesar 0,70\%, $0,85 \%$, dan $1,25 \%$ dengan perpanjangan waktu yang diberikan pihak bank kepada nasabah yang menunggak. Meskipun secara perhitungan analisisnya, Non Performing Loan (NPL) juga mengalami peningkatan. Untuk meminimalisir kredit bermasalah, maka pihak bank PT. Bank Negara Indonesia 1946 (Persero) Tbk mengeluarkan kebijakan restrukturisasi sebagai solusi bagi masyarakat yang tidak dapat melunasi hutangnya dengan tepat waktu.

\section{SIMPULAN} berikut:

Berdasarkan analisis perhitungan rasio keuangan dapat disimpulkan sebagai

Loan to Deposit Ratio PT. Bank Negara Indonesia (Persero) Tbk. Pada periode 2017 - 2019 mengalami peningkatan secara berturut-turut sebesar $85 \%$, $89 \%$, dan $92 \%$, artinya bank BNI selama tiga tahun terakhir termasuk cukup sehat. Dimana Loan Deposit to Ratio (LDR) berdasarkan standar kriteria Bank Indonesia tidak melampaui batas maksimum yaitu $120 \%$. Ini membuktikan bahwa bank mampu mengelola likuiditas dalam menghimpunkan dana dan memberikan pinjaman kepada debitur dengan baik. Sedangkan Non Performing Loan (NPL) perode 2017 - 2019 dengan persentase berturut-turut $0,70 \%, 0,85 \%$ dan $1,25 \%$ sesuai dengan kriteria ketentuan Bank Indonesia yaitu NPL $<5 \%$, artinya bank dalam keadaan sehat. Ini membuktikan bahwa bank mampu mengelola kredit dengan baik sehingga dapat memberikan pinjaman kepada masyarakat. 


\section{UCAPAN TERIMA KASIH}

Penulis mengucapkan terima kasih kepada semua pihak yang telah bersedia membantu penulis dalam penyelesaian artikel ini.

\section{DAFTAR PUSTAKA}

Alanshari, F., \& Marlius, D. (2018). Prosedur Pemberian Kredit KPR Pada PT. Bank Tabungan Negara (Persero) TBK Cabang Pembantu Bukittinggi. https://doi.org/10.31227/osf.io/rsfhc

Amelia, L., \& Marlius, D. (2018). Pengendalian Kredit Dalam Upaya Menciptakan Bank Yang Sehat Pada PT. Bank Pembangunan Daerah Sumatera Barat Cabang Utama Padang. https://doi.org/10.31227/osf.io/kpc64

Asyari, A., \& Marlius, D. (2021). Proses Penyelesaian Kredit Bermasalah Pada PT. BPD Sumatera Barat Cabang Pasar Raya Padang. https://doi.org/10.31219/osf.io/3hfcr

Republik Indonesia Tahun 1998 Tentang Perbankan. Jakarta: Sinar Grafika.

Pasaribu, H., \& Sari, R. L. (2011). Analisis Tingkat Kecukupan Modal Dan Loan To Deposit Ratio Terhadap Profitabilitas. Jurnal Telaah \& Riset Akuntansi, 4(2), 114-125.

Puspitasari, D. (2009). Analisis Pengaruh CAR, NPL, PDN, NIM, BOPO, LDR, Dan Suku Bunga SBI terhadap ROA (Studi pada bank devisa Di Indonesia perioda 2003-2007). Program Pascasarjana Universitas Diponegoro.

Shanjaya, A. R., \& Marlius, D. (2017). Peranan Laporan Keuangan Dalam Kebijaksanaan Pemberian Kredit Kepada Calon Nasabah Pada PT. BPR Batang Kapas. https://doi.org/10.31227/osf.io/uxmg6

Soebagio, H. (2005). Analisis Faktor-Faktor Yang Mempengaruhi Terjadinya Non Performing Loan (NPL) Pada Bank Umum Komersial (Studi Empiris pada Sektor Perbankan di Indonesia). Program Pascasarjana Universitas Diponegoro.

Widayati, R., \& Maiwati, S. (2019). Aktivitas Pemberian Kredit Komersil Pada Bank Nagari Cabang Sijunjung.

Widayati, R., \& Mendari, W. E. (2019). Upaya Penanganan Kredit Bermasalah Pada Bank Nagari Cabang Utama Padang. 1-12. https://doi.org/10.31219/osf.io/ewm65

Yati, H., \& Afriyeni, A. (2019). Analisis Loan To Deposit Ratio Dan Non Perfoming Loan Pada Pt. Bank Pembangunan Daerah (BPD) Sumatera Barat Cabang Utama Padang. 1-12. https://doi.org/10.31219/osf.io/vpq36 